\title{
Determinants of Consumer Patronage for Ghana Grown Chicken
}

\author{
Stephen Opoku-Mensah ${ }^{1}$, Siegfried Affedzie-Obresi ${ }^{2}$, Hayford Agbekpornu ${ }^{3}$ \\ ${ }^{1}$ Agropreneurship Department, Institute of Entrepreneurship and Enterprise Development, Kumasi Polytechnic, P.O.Box 854, Kumasi \\ ${ }^{2}$ CSIR-Animal Research Institute, P. O. Box AH20 Achimota, Accra
}

${ }^{3}$ Fisheries Commission, Ministry of Fisheries and Aquaculture Development, Accra

\begin{abstract}
Consumer demand and preference for high value food products including chicken has increased dramatically, especially for many emerging economies including Ghana. In this study, data collected from 180 respondents in the Kumasi Metropolis were subjected to qualitative and quantitative analysis, to measure the chicken consumption patterns and the key determinants of consuming Ghanagrown chicken. The results revealed that chicken is consumed on a more regular basis, with a high preference for 'live' chicken. The major attributes of Ghana-grown chicken preferred by consumers includes the health, safety, nutritional value, and taste of chicken. The buying decision of chicken consumers was ranked in descending order of preference as safety, nutritional value, and form (live or processed) whiles price and country of origin were the least ranked. Consumers have a generally good perception of and positive attitude towards the patronage of Ghana chicken, as they perceived Ghana chicken to be grown under ethical conditions even though they rated it to be more expensive than the imported. Results of econometric analysis revealed that gender, safety, trust and the price of chicken were the major determinants that influenced consumer preference for Ghana chicken. This study recommends that policy direction towards value-addition through processing, innovative marketing strategies and a strong consumer advocacy that would significantly improve consumption of Ghana-grown chicken.
\end{abstract}

Keywords: Ghana-grown chicken, chicken attributes, consumer preference, Kumasi metropolis

\section{Introduction}

The huge demand for and consumption of poultry (chicken) across emerging economies, including Ghana is driven largely by rapid population growth, increasing urbanization, enhanced living standards and an emerging middle class society that prefers high value food products. Chicken can therefore be appropriately tagged as „lifestyle food ${ }^{\text {ee }}$ commodity in a country like Ghana. Consumption of poultry meat increased from $125,000 \mathrm{MT}$ to $300,000 \mathrm{MT}$ between the years 1990-2000. The trend witnessed a dramatic surge between the years 2001-2010 with consumption reaching 2.5 million MT per annum (SRID-MoFA, 2010). Regrettably, however the share contribution from the domestic poultry industry to total poultry consumption in Ghana has dwindled from about $80 \%$ in the $1980^{\text {ce }}$ s to about $10 \%$ as at 2010 (Randon and Ashitey, 2013 and SRIDMoFA, 2012). The domestic poultry industry has thus not been able to match the huge market demand with local supplies, hence the massive influx of the cheap poultry products. Some of the reasons attributed to the dwindling performance of the local poultry sector include high input cost (Randon and Ashitey, 2013 and SRID-MoFA, 2010), production inefficiencies (Randon and Ashitey, 2013), poor market integration (Leturque, 2012; Diao et al, 2010), lack of adequate processing facilities and value addition to products (Randon and Ashitey, 2013 and Diao et al, 2010) and an underdeveloped poultry value chain. Although chicken exhibit high income elasticity (Leturque and Wiggin, 2011), per capita consumption of the commodity has risen by over $315 \%$ in the last 10 years (FAO, 2010) as a result of changes in consumption patterns driven by urbanization (Angelucci et al, 2013).
Advocates of consumption of local food products argue that the unbridled imports of cheap poultry products have contributed to the massive decline in domestic supply, distortion of inter-market price transmission and consequently the near collapse of the industry with small scale farmers being the most affected. Proponents of free trade and for that matter imported chicken however, claim that imports enable consumers to enjoy more convenient, differentiated, and high quality products, at a much cheaper rate. Thus whiles consumption of poultry products keep rising, the domestic supply base has not been able to capture a significant share of the consumer demand, and this has attracted the attention of government, value chain actors and others particularly pro-development civil society organizations. The most critical issue here is whether the domestic poultry industry has the capacity to meet this challenge from the supply side and most importantly, whether Ghanaian consumers are prepared and ready to patronize locally produced chicken.

\subsection{Problem Statement}

Poultry products (described in this study as commercially produced broiler and layer meat) are now becoming convenient and ,lifestyle food ${ }^{\text {ee }}$ commodities for most urban and suburban Ghanaian consumers. The per capita consumption of chicken has increased from $12 \mathrm{~kg}$ in 2001 to $45 \mathrm{~kg}$ in 2010 (FAO, 2010). Consumption of chicken in Ghana is projected to grow by between $30-35 \%$ in the next 10 years (Randon and Ashitey, 2013 and FAO, 2012). The rather high over-dependence on imported processed chicken has attracted the attention of governments, civil society organizations, the general populace and indeed a matter of public discussions in recent times. Ghanaians have acquired and developed a taste for processed chicken as evidenced by the massive import of the commodity. The imported chicken 


\section{International Journal of Science and Research (IJSR) \\ ISSN (Online): 2319-7064 \\ Index Copernicus Value (2013): 6.14 | Impact Factor (2014): 5.61}

also tends to be cheaper, more conveniently packaged and readily available (Kwadzo et al, 2013 and Egyir et al, 2012). On the contrary, there appears to be a growing preference for live chicken (which is largely obtained domestically) especially during festive occasions like Christmas, Ramadan, etc. Given the present and projected rate of consumption, it would be interesting to ascertain exactly what factors determine the patronage of chicken meat amongst the Ghanaian consumers. The country may be able to make some savings on foreign exchange whiles resuscitating the ,dying ${ }^{\text {ee }}$ poultry industry.

The fundamental question that this study seeks to address is the extent to which consumers are willing and ready to patronize Ghana grown chicken. What are the general consumption patterns of chicken by Ghanaians? Are Ghanaians willing to patronize domestically produced chicken? If they are willing, what factors influence consumer patronage of locally grown chicken? This study would attempt to address these issues and suggest ways of improving local consumption of Ghana food products including chicken.

\subsection{RESEARCH OBJECTIVES}

The main objective of this study is to determine the willingness of Ghanaian consumers to patronize Ghana grown chicken. The specific objectives of the paper are:

(i) To examine the consumption patterns of chicken by respondents in the Kumasi Metropolis

(ii) To analyze the perception and attitude towards patronage and consumption of chicken.

(iii) To measure and quantify the factors that influence patronage of Ghana-grown chicken.

\section{Determinants of Consumer Demand, Consumption and Preference for Chicken}

Empirical researches on consumer preference for food commodities (especially high value food products), though copious in advanced economies, are very few in most developing countries including Ghana. However, the key determining factors that influence consumption patterns in developing countries may not differ any significantly from that exhibited in the advanced economies. This brief review of literature therefore focuses on the conventional theories and factors that have been advanced in consumer choice studies especially for food products with particular reference to socio-economic characteristics, food product attributes, price and ethnocentric sentiments. The analysis partly agrees with and follows the new consumer behaviour theory originally developed or suggested by Lancaster (1996), which postulates that products are consumed based on the attributes they possess, other than the product itself and are associated with consumer preferences and utility. Thus consumers $^{\text {ce }}$ evaluate a product based on intrinsic and extrinsic attributes of the food product.

Gallup (2008) and Prestat (2001) have asserted that consumer perception of extrinsic attributes of meat products such as price, brand name, promotion, packaging, country of origin (Dopico and Acebron, 1999) and intrinsic cues such as freshness, visible fatness, color, perceived food safety, texture, are very important considerations in making food buying decisions. For meat products like poultry, consumers are particular about nutritional attributes such as amino acid content, meat quality (Almeida et al, 2009 and Fletcher, 2002); sensorial features like color, smell, flavor, juiciness, freshness, taste (Sow and Grognet, 2010); tenderness, leanness, meatiness, health, nutrition, (Grunert, 1997); and fat and cholesterol content (Ava, 2003). In a conjoint analysis of consumer preference for broiler meat in Ghana, Kwadzo et al (2013) revealed that the most important attributes considered by consumers were the form of broiler meat, availability, price, taste and proximity respectively. In that same study, it was shown that whiles locally produced broiler was ranked topmost for its taste, consumers scored/ranked imported broiler meat higher in terms of price, availability, proximity, and packaging. Household income is also a major determinant of the amount, type and quality of food purchased. Egyir et al. (2012) in a study of Ghanaian consumer choice for ,made in USA ${ }^{\text {ce }}$ labeled chicken concluded that product packaging, meat quality and expiry date greatly influenced consumers ${ }^{\text {ee }}$ decisions and that ethnocentrism and country of origin do not influence consumer choice of broiler meat. Consumer sophistication in Ghana is gradually increasing, and so is their expectation of attributes such as safety, health, quality, taste, packaging and labelling, convenience, and country of origin (,made-in ${ }^{\circ}$ ) since these play an important role in food choice decision. However, it must be quickly noted that, for most consumers, these attributes and preferences are subject to the individuals ${ }^{\text {ee }}$ budgetary constraints (Padel and Foster, 2005). Indeed, Mahgoub et al., (2007) revealed that for most low income earners, food price was a major determinant of food types purchased. Philips et al., (2010) and Charles (2002) have shown that the price, country of origin, taste and expiry date of food products plays a significant role in food purchasing behaviour of consumers.

\section{Research Methodology}

\subsection{Study Area and Location}

The study was carried out in Kumasi, which is the second largest city of Ghana. Kumasi lies between longitude $0^{\circ}$ $15^{\mathrm{e}} \mathrm{W}-2^{\circ} 15^{\mathrm{ee}}$ and latitude $6^{\circ} \mathrm{N}-7^{\circ} 30^{\mathrm{e}} \mathrm{N}$ of the equator. The city is a typical cosmopolitan area, somewhat geographically located at the centre of Ghana and has an estimated population of about 670,000, according to the 2010 National Housing and Population Census by the Ghana Statistical Service, (GSS, 2012). Though there is a growing corporate and business group with its emerging middle class consumers, commerce, trade, agribusiness, and light artisanal micro-enterprises predominantly within the informal sector amply describe the city of Kumasi. This class of individuals constitutes a formidable consumer entity for the patronage of chicken meat.

\subsection{Sampling Techniques and Procedures}

In selecting a sample for this research, both probability and non-probability sampling method was adopted. The study used a combination of purposive and random sampling techniques to select respondents, from a cross section of the working class group from the formal and informal sector within the metropolis. More specifically, the research 


\section{International Journal of Science and Research (IJSR) \\ ISSN (Online): 2319-7064 \\ Index Copernicus Value (2013): 6.14 | Impact Factor (2014): 5.61}

targeted the working class population who consume chicken or patronize chicken products in one form or the other.

\subsection{Methods of Data Collection}

The main data collection instrument used in this study was well structured, mostly close-ended questionnaires and face to face interviews. A total of 180 respondents were interviewed in the research. Some of the important data sets collected were the socio-economic variables, consumption habits, the perceptions and attitudes of consumers towards imported and Ghana grown chicken. A Likert scale item was used to ascertain and measure respondents ${ }^{\text {ee }}$ degree of agreement to specific items bordering on perception and attitudes towards chicken consumption. On a five - point Likert scale, consumers were asked to rate their perceptions on whether they ,strongly agree $-5^{\text {ee }}$ to ,strongly disagree $1^{\mathrm{ee}}$.

\subsection{Analytical Techniques and Methods.}

Data collected were analyzed using both qualitative and quantitative methods. Qualitative analysis involved the use of simple descriptive statistics like percentages, mean, pie charts and graphs to determine the socio-economic characteristics of respondents and consumption patterns. A Logit regression analysis was performed to measure the relationship between a number of selected independent variables and the willingness of consumers to patronize Ghana chicken.

\subsubsection{Discrete Choice Model - Logistic Regression Model} Choice modelling predicts a consumeres behaviour by determining the relative importance of various attributes in consumers $^{\text {ee }}$ decision making process (Ara, 2003). A random utility model, Probit or Logit can therefore be applied where binary responses are encountered. The Logit model is a common mathematical function that has been used empirically to determine consumer choices that provide estimates of utility consumers derive on different choices or alternatives (McFadden, 1974). In this Logistic regression model, the dependent variable (preference for domestic chicken or imported chicken) is regressed on a number of independent variables categorized into socio-economic characteristics and product (chicken) attributes. The use of random utility model assumes that the decision maker has a perfect discrimination capability, however the researcher usually has incomplete information and therefore uncertainty must be taken into account. Uncertainty is the result of unobserved taste variations, measurement errors and instrumental variables (Manski, 1997).

According to Greene (2002), typical choice models such as Logit and Probit are based on random utility where the ith consumer is exposed to $j$ choices. If the utility function of $j$ is $U i j$, then

$$
U_{i j}=\sum \beta_{1} X_{i j}+\varepsilon_{i j}
$$

where $X i j$ is a vector of a particular characteristic of consumers who make a particular choice decision, $\beta$ is vector of parameters to be estimated and $\varepsilon i j$ are error terms. Based on the behavior of unobservable responses for other choices, when responding to a particular choice, Greene (2002) specifies the binomial Logit Model as:

$$
U_{i j}=\sum_{1}^{n} X_{i}^{\prime} \quad \beta_{1} X_{i j}+\varepsilon
$$

\subsubsection{Specification of the Econometric Model}

The Logit regression model in practice has been used by many researchers because of its comparative mathematical simplicity. Following Brooks (2008) and Maddala (1983), the cumulative logistic probability model is econometrically specified as:

$$
P_{i=} F\left(Z_{i}\right)=F\left(a+\sum_{i=1}^{n} \beta_{i} X_{i}\right)=\frac{1}{1+e^{-z_{i}}} \ldots \ldots
$$

Where, $P i=$ probability that an individual indicates willingness to consume Ghana chicken, $X_{i}$.

$X_{i}=$ represents the $i^{\text {th }}$ explanatory variables

$e=$ denotes the base of natural logarithms, which is approximately equal to 2.718

$\alpha$ and $\beta_{i}$ are parameters to be estimated.

The model can be linearized by taking the natural logarithm of the odds ratio in equation (3), which results in the Logit model specified as:

$$
W T P G G C_{i}=\operatorname{Ln}\left(\frac{P_{i}}{1-P_{t}}\right)=\alpha+\beta_{i} X_{i}+\beta_{2} X_{2}+\cdots+\beta_{n} X_{n} \cdots \cdots
$$

Where $W T P G G C_{i}$ is an expression of consumer decision or willingness to patronize Ghana chicken or not, $P_{i}$ is the household socio-economic, demographic, institutional, and communication characteristics. probability of the events occurrence, $X_{i}$ is a vector of

$$
\begin{array}{r}
\text { WTPGGC }_{i}(1 / 0)=\beta_{0}+\beta_{1} *(\text { AGE })_{i}+\beta_{2} *(\text { GENDER })_{i}+\beta_{3} *(\text { HEALTHGC })_{i} \\
+\beta_{4} *(\text { SAFETYGC })_{i}+\beta_{5} *(\text { TASTEGC })_{i}+\beta_{6} *(\text { PRICEGC })_{i} \\
+\beta_{7} *(\text { TRUSTGC })_{i}+\beta_{8} *(\text { MINCOME })_{i}+\varepsilon \ldots(5)
\end{array}
$$

$\beta_{0}$ is a constant, are corresponding vectors of regression and

$\varepsilon$ is disturbance term as shown in equation (5). 


\section{International Journal of Science and Research (IJSR) \\ ISSN (Online): 2319-7064 \\ Index Copernicus Value (2013): 6.14 | Impact Factor (2014): 5.61}

Table 1: Description of Variables used in Regression of Access to Credit by Agri-SME ${ }^{e c}$

\begin{tabular}{|c|c|c|}
\hline Variable & Description of Explanatory Variables & A Priori \\
\hline $\begin{array}{l}\text { WTPGGC } \\
\quad A G E\end{array}$ & $\begin{array}{l}\text { Willingness to patronize Ghana grown } \\
\text { chicken } 1=\text { yes and } 0=\text { no } \\
\text { Age of respondent (yrs) }\end{array}$ & $+/-$ \\
\hline GENDER & Sex of respondent $1=$ male; $0=$ female & + \\
\hline HEALTHGC & $\begin{array}{l}\text { Ghana chicken is healthy } 1 \text { = strongly } \\
\text { disagree } \ldots 5=\text { strongly agree }\end{array}$ & + \\
\hline TASTEGC & $\begin{array}{c}\text { Ghana chicken is tasty } 1=\text { strongly } \\
\text { disagree } \ldots 5=\text { strongly agree }\end{array}$ & + \\
\hline SAFETYGC & $\begin{array}{c}\text { Ghana chicken is safer } 1=\text { strongly } \\
\text { disagree } \ldots 5=\text { strongly agree }\end{array}$ & + \\
\hline TRUSTGC & $\begin{array}{c}\text { Ghana chicken can be trusted } 1= \\
\text { strongly disagree } \ldots .5=\text { strongly agree }\end{array}$ & + \\
\hline PRRICEGC & $\begin{array}{c}\text { Ghana chicken is expensive } 1=\text { strongly } \\
\text { disagree } \ldots 5=\text { strongly agree }\end{array}$ & + \\
\hline MINCOME & $\begin{array}{l}\text { Estimated monthly income of } \\
\text { respondent }(\mathrm{GH} \Phi)\end{array}$ & + \\
\hline
\end{tabular}

\section{Results and Discussion}

\subsection{Socio-economic Characteristics of Consumers in the Study Area}

The study to ascertain the consumer preference and determinants of consumption of Ghana grown chicken involved 180 respondents. There were 84 (46.7\%) males and 96 (53.3\%) females involved in the study whose ages ranged between 22 and 70 giving a mean age of 41.24 years. Most of the respondents, about $71 \%$ were married, with a literacy rate of $94 \%$, were mostly Christians (73\%) and were all employed either in the public sector, private sector or operated as entrepreneurs. Majority of the respondents (86\%) were either breadwinners or co-breadwinners and had a mean household size of 4.68 persons.

\subsection{Chicken Consumption Patterns and Preferences of Respondents in the Study Area}

The specific issues discussed in the first objective are a qualitative analysis of the consumption patterns and frequency, the preferred attributes, and purchasing behaviour of consumers of chicken in Ghana.

\subsubsection{Chicken Consumption Patterns and Frequency}

The analysis showed that out of the 180 respondents, $14.4 \%$ consumed chicken on a daily basis, $47.8 \%$ on a weekly basis, $28.9 \%$ on a monthly basis with only $8.8 \%$ consuming chicken bi-annually or annually (Table, 2). This result agrees with the findings and assertion of Egyir et al (2012) and Umberger et al (2012) that chicken now forms or constitutes a regular source of protein especially for many urban dwellers, consumption of which is fuelled by the proliferation of several fast food joints around the cities. When respondents were asked to indicate the form or state in which chicken was purchased, 21\% indicated that they purchased it in the live form, 35\% purchased in the processed form and 44\% purchased both live and processed chicken. However, when respondents were asked to indicate their preferred form of chicken about $62 \%$ opted for live chicken, $16 \%$ chose processed and $22 \%$ stated their preference for either live or processed forms. The rather sharp contrast between the current purchased and preferred form of chicken, though confusing is not surprising as most respondents perceived that, Ghana or locally grown chicken (which usually came in the live form) was better or had preferred attributes (either intrinsic or extrinsic) than imported frozen processed chicken. Indications here are that, there is a preference for commercially produced chicken in Ghana as opposed to imported frozen types. The capacity of producers, distributors, and marketers of poultry products to add value through processing of locally produced chicken is critical at this stage to meet the seemingly favourable preference for Ghana grown chicken.

Table 2: Consumption Patterns of Chicken by Respondents

\begin{tabular}{|c|c|c|}
\hline Item & Frequency & Percentage \\
\hline Rate of chicken consumption & & \\
\hline Daily & 26 & 14.4 \\
\hline Weekly & 86 & 47.8 \\
\hline Monthly & 52 & 28.9 \\
\hline Biannually & 8 & 4.4 \\
\hline Annually & 8 & 4.4 \\
\hline Form in which Chicken is purchased & & \\
\hline Live bird & 37 & 20.6 \\
\hline Processed-Dressed & 63 & 35.0 \\
\hline Both Live and Dressed & 80 & 44.4 \\
\hline Preferred Form of Chicken & & \\
\hline Live & 112 & 62.2 \\
\hline Dressed-Processed & 28 & 15.6 \\
\hline Don't really care & 40 & 22.2 \\
\hline Source: Field stur, 2014 & &
\end{tabular}

Source: Field study, 2014

\subsubsection{Preferred Attributes of Chicken as Indicated by Respondents}

The study also sought to ascertain the major attributes of chicken preferred by consumers. The results as presented in Figure 1 shows that the most important attributes considered by consumers were safety and health reasons (71.6\%), followed by nutritional value (70.1\%), and 56\% citing taste and texture (Figure 1). The least factors considered by consumers were the form or state of chicken (44.1\%), palatability (36.6\%) and source of chicken (24.9\%). Thus consumer concerns and preference for chicken are driven more by attributes such as the health, safety, taste and nutritional value and that source or country of origin is not a major consideration, which corroborates with the assertions of Sow and Grognet 2010; Almeida et al, 2009; Gallup (2008), Prestat (2001), and Egyir et al (2012). 


\section{International Journal of Science and Research (IJSR) \\ ISSN (Online): 2319-7064}

Index Copernicus Value (2013): 6.14 | Impact Factor (2014): 5.61

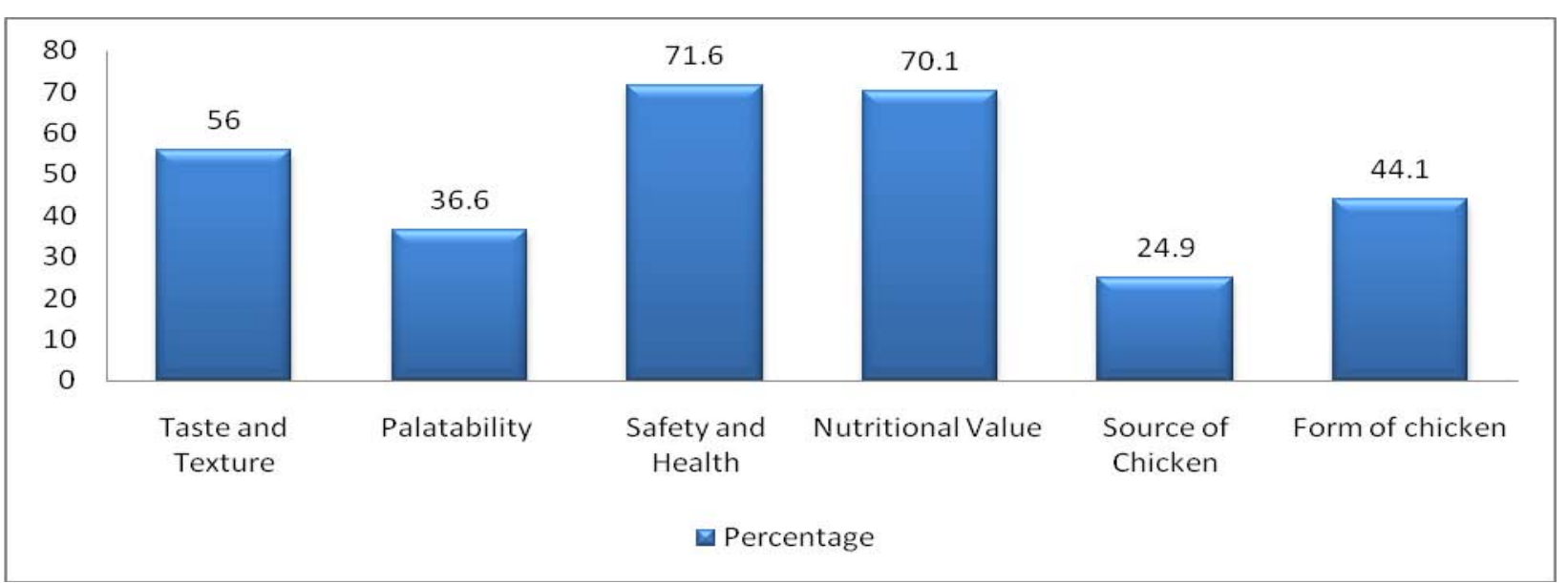

Figure 1: Distribution of Selected Preferred Attributes of Chicken by Respondents

Source: Field Study Survey, 2014

The study prospected further to measure the order of preference in the buying decisions of respondents by asking them to rank (from $1^{\text {st }}$ to $6^{\text {th }}$ ) the most important considerations based on some six selected attributes. A Friedman"s test of ranks showed an overall highly significant outcomes of the rankings with a $\chi^{2}=167.78$; and $d f=5$ and $p<0.001$ (Table 3). Consumers therefore considered the safety, nutritional value, form (live or processed) and convenience of chicken, to be more important decision criteria than the price and country of origin of chicken, which is similar to results reported by Egyir et al (2012) but contrary to the findings of Kwadzo et al (2013) who showed that price is the most important attribute influencing consumer preference for Ghana chicken..

Table 3: Purchase Decision-Ranking of Selected Attributes of Chicken Preferred by Consumers

\begin{tabular}{|c|c|c|}
\hline Factors or Attributes & Mean Rank & Position \\
\hline Form - live or processed & 3.41 & 3 \\
\hline Convenience - cut portions, package & 3.73 & 4 \\
\hline Safety and health & 2.14 & 1 \\
\hline Source or country of origin & 4.68 & 6 \\
\hline Price & 4.55 & 5 \\
\hline Nutritional value & 2.50 & 2 \\
\hline
\end{tabular}

Test Stats: $\mathrm{N}=108 ; \chi^{2}=167.78 ; d f=5 ;$ Asymp Sig .000 $(P<5 \%)$

Table 5: Likert Scale Response on Perceived Attributes of Ghana Grown Chicken $(\alpha=0.943)$

\begin{tabular}{|l|c|c|c|c|c|c|c|}
\hline \multicolumn{1}{|c|}{ Selected Attributes or Factors } & $\begin{array}{c}\text { Strongly } \\
\text { Disagree }\end{array}$ & Disagree & Fair & Agree & $\begin{array}{c}\text { Strongly } \\
\text { Agree }\end{array}$ & Mean & S.D \\
\hline Ghana Chicken meat is safer than imported & 4 & 10 & 14 & 37 & 35 & 3.89 & 1.13 \\
\hline Ghana chicken is more tastier & 3 & 9 & 16 & 36 & 35 & 3.9 & 1.09 \\
\hline Ghana chicken is not contaminated & 2 & 11 & 22 & 39 & 26 & 3.76 & 1.03 \\
\hline Ghana chicken meat is less fatty & 1 & 8 & 18 & 51 & 23 & 3.88 & 0.86 \\
\hline Ghana chicken meat is healthier & 2 & 14 & 13 & 42 & 29 & 3.82 & 1.05 \\
\hline Ghana poultry meat is produced ethically & 2 & 9 & 18 & 36 & 35 & 3.91 & 1.05 \\
\hline Price of Ghana poultry meat is high & 1 & 10 & 11 & 46 & 32 & 4.00 & 0.95 \\
\hline Ghana poultry meat can be trusted & 5 & 9 & 13 & 37 & 36 & 3.86 & 1.47 \\
\hline
\end{tabular}

\subsection{Determinants of Willingness to Patronize Ghana Grown Chicken}

A Logit regression analysis was performed to determine the factors that influenced the willingness or propensity of consumers to patronize Ghana grown chicken. The study analyzed a number of demographic characteristics and

\subsection{Consumer Perception of Ghana Grown Chicken}

The second objective of this study was to determine and measure the perception of consumers on some selected attributes of chicken meat produced in Ghana. A descriptive statistics of Likert scale response, on a scale of $1-5$ was used to analyze data. A reliability test of the Likert scale items was favorable with an overall Cronbach's Alpha value of 0.943 . The results as presented in Table 5 revealed that consumers had a generally positive attitude and propensity towards Ghana grown chicken with an overall mean score of (3.88). The analysis revealed that more than $50 \%$ of the respondents scored or voted to either 'agree' or 'strongly agree' to all the listed statements of the attributes for Ghana grown chicken. For example, the study revealed that there is a high perception amongst consumers that Ghana chicken is highly priced and this had a mean score of (4.0), chicken is grown under ethical conditions (eg no use of growth hormones) (3.91), Ghana chicken is tastier (3.90), it is much safer and healthier (3.89) and can be trusted (3.88). The mean scores for the statements (captured in brackets) confirms yet again that health, safety, taste and trust are important attributes consumers look out for, as opposed to price. The fact that all the respondents belong to the working class must have influenced the outcome of these responses.

\section{Volume 5 Issue 3, March 2016}




\section{International Journal of Science and Research (IJSR) \\ ISSN (Online): 2319-7064 \\ Index Copernicus Value (2013): 6.14 | Impact Factor (2014): 5.61}

product, ability to assess the state of the bird (as „live ${ }^{\mathrm{ce}}$ ), and less fat content. In a follow up question, approximately $86 \%$ of respondents declared their willingness to support the patronage of Ghana chicken. Finally, when respondents were asked to indicate the degree of willingness to patronize Ghana chicken, 131 (72.8\%) indicated they were either 'highly willing' or 'very willing' to patronize Ghana chicken as opposed to the extreme $15(8.3 \%)$ who indicated they were 'less willing' or ,not willing at all'. An overall assessment of this analysis indicates that consumers have a positive and favourable disposition towards patronizing and consuming Ghana grown chicken, at least on the basis of this descriptive test.

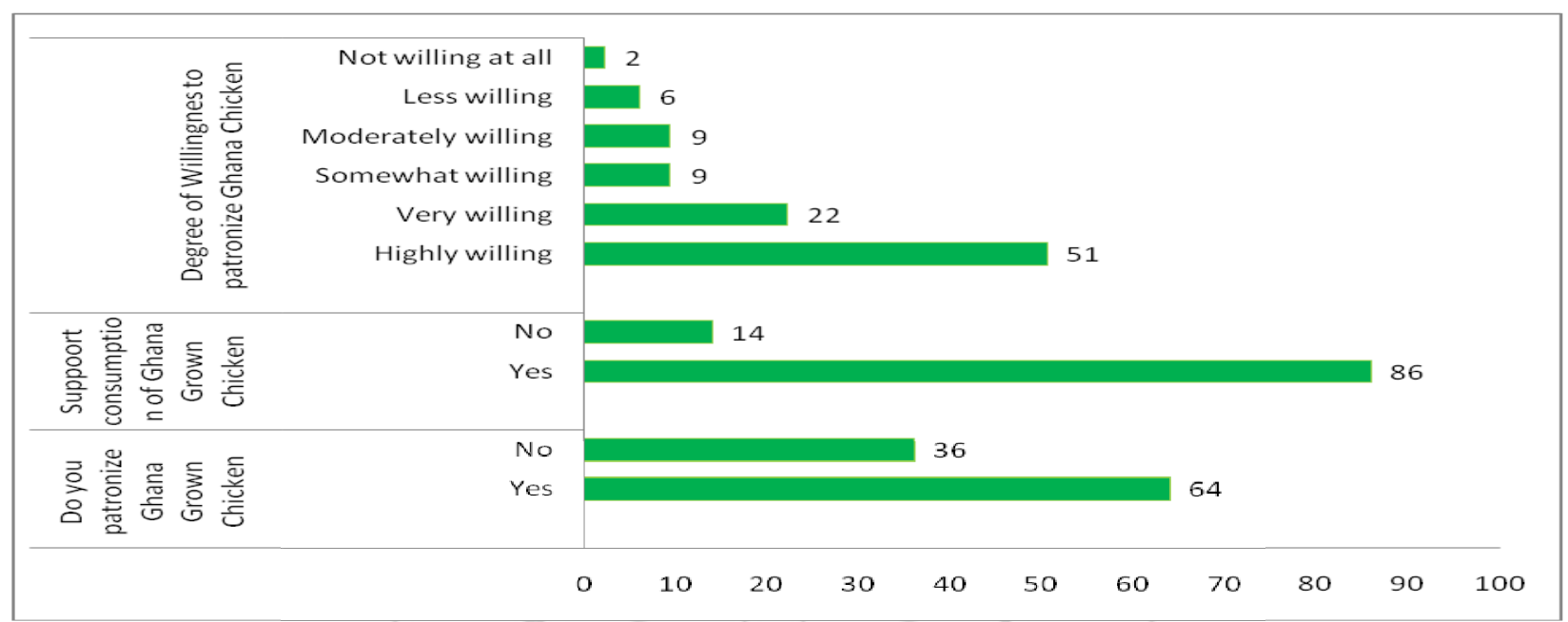

Figure 3: Percentage Distribution of Consumer Willingness to Patronize Ghana Grown Chicken

The Logit regression result is presented in Table 7. The analysis showed that the model was able to correctly predict the choices made by the respondents in the model $77 \%$ of the times. In all 180 consumers of chicken were involved in the study, with 134 (86\%) indicating patronage of Ghana chicken and 76 (14\%) not patronizing. The Logistic model was found to be the appropriate model $(\chi 2=40.529 ; \mathrm{df}=8$; $\mathrm{p}<0.001$; Hosmer-Lemeshow goodness of fit chi square 7.832; and $\mathrm{p}$ value 0.450 ) with the model giving an overall correct prediction of $77 \%$ (44.9\% for non-consumers and $90.7 \%$ for consumers of Ghana chicken). Employing a 0.05 criterion of statistical significance, the results show that four explanatory variables (gender, TrustGC, SafetyGC and
PriceGC) out of the eight explanatory variables significantly influenced consumer choice of Ghana grown chicken. The results showed that the gender variable yielded an odds ratio of 3.240, which suggest that holding all other variables constant, males are 3.24 times more likely, to patronize Ghana chicken than females and this was significant at 5\% level. Similarly, respondents who consumed Ghana chicken were 2.484 times more likely to trust in Ghana chicken than non-consumers and this was also significant at 5\% level. Lastly, when the price of chicken is raised by GH\&1, the odds ratio is 4 times as large and therefore consumers of Ghana chicken are 4 times more likely than non-consumers to patronize Ghana chicken.

Table 7: Logit Regression Results of Consumer Willingness to Patronize Ghana Grown Chicken

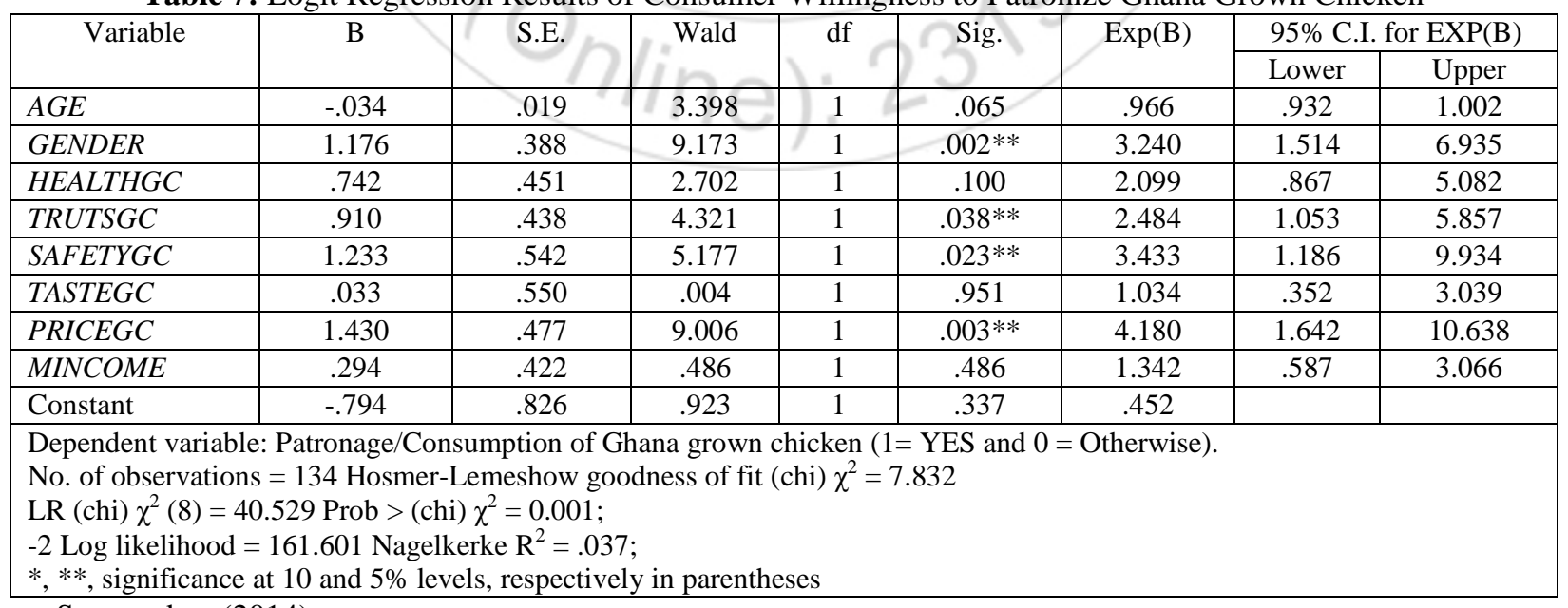

Source: Survey data (2014).

\section{Conclusion and Recommendations}

This study was conducted in the Kumasi Metropolitan Area to examine the chicken consumption patterns and the factors that influence patronage of Ghana grown chicken The study revealed that consumption of chicken meat now forms part of the regular meal of many consumers, with the most important attributes sought for being the taste, health and safety, nutritional value, and trust. Ghanaian consumers have

\section{Volume 5 Issue 3, March 2016}




\section{International Journal of Science and Research (IJSR) \\ ISSN (Online): 2319-7064 \\ Index Copernicus Value (2013): 6.14 | Impact Factor (2014): 5.61}

shown a very high preference for and positive attitude towards Ghana grown chicken, with the most important factors or reasons being that the product is grown under ethical conditions, it is healthier, safer and can be trusted than imported frozen chicken. The major factors that significantly influenced patronage of Ghana grown chicken were the gender, trust, safety and price of chicken meat. Policy makers, poultry value chain actors together with other stakeholders should emphasize on consumer advocacy to support consumption of local poultry since it is highly preferred and enjoys a positive attitude from consumers.

\section{References}

[1] Angelucci F., Asante - Poku A. and Anaadumba P., (2013). Analysis of incentives and disincentives for rice in Ghana. Technical notes series, MAFAP, FAO, Rome.

[2] Ara, S. (2003). Consumer Willingness-To-Pay for Multiple Attributes of Organic Rice: A Case Study in the Philippines. Annual Meeting, August 16-22, 2003, Durban, South Africa, International Association of Agricultural Economists

[3] Ava, R. (2003). Sensory Aspects of Consumer Choices for Meat and Meat Products. Meat Science, 66, pp. 1120

[4] Almeida, I.L, Junqueira, A.M.R. and Zamudio, L.H.B. (2009). Consumers ${ }^{\text {ee }}$ Evaluation and Perception of Chicken Meat Quality in Brasilia, Brazil as a Function of Family Income, Proceeding of $\mathrm{VII}^{\text {th }}$ International PENSA Conference, Nov. 26-28, 2009, Sao Paolo, pp. 1-14.

[5] Brooks C. (2008). Introductory Econometric for Finance. (Edn no) Cambridge; Cambridge University Press

[6] Diao, X. et al. The Role of Agriculture in African Development, World Development (2010), doi:10.1016/j.worlddev.2009.06.011

[7] Food and Agriculture Organisation (FAO) (2006). "Briefs on Import Surges - Countries No.5 Ghana: Rice, Poultry and Tomato Paste".

[8] Dópico C.D. and B.L Acebrón (2000). The Importance of Intrinsic and Extrinsic Cues to Expected and Experienced Quality: An Empirical Application for Beef. Food Quality and Preference 11 (2000) 219 238.

[9] Fletcher, D.L. (2002). Poultry Meat Quality, World's Poultry Science Journal, 2002, 58 (2), pp. 131

[10] Gallup (2008). The 2008 Gallup Food Safety Study. Gallup, Washington,

D.C. www.gallup.com/6424/Nutrition-Food.aspx

[11] Green H.W. (2002). Econometric Analysis, $5^{\text {th }}$ Edition, Prentice-Hall, Upper Saddle River, New Jersey. PP. 663-708.

[12] Grunert, K.G. (1997). What's in a steak? A CrossCultural Study on the Quality Perception of Beef. Food Quality and Preference 8 (3): 157-174.

[13] Egyir, I.S, Adu-Nyako, K. and Okafor, R. (2012). The "Made in USA Poultry Label" and Consumer C hoice in Ghana, Selected Paper Prepared for Presentation at the Southern Agricultural Economics Association Annual Meeting, Birmingham, AL, February 4-7, 2012

[14] Kwadzo, G.T-M., Dadzie, F., Osei-Asare, Y.B. and Kuwornu, J.K.M. (2013). Consumer Preference for
Broiler Meat in Ghana: A Conjoint Analysis Approach. International Journal of Marketing Studies; Vol. 5, No. 2

[15] Lancaster, K.J. (1966). "A New Approach to Consumer Theory." Journal of Political Economy 74(2).

[16] Leturque, H. and Wiggins, S. (2010). Ghana's Sustained Agricultural Growth: Putting Underused Resources to Work. Development Progress Project, ODI.

[17] MacFadden, D. (1974). "Econometric Models for Probabilistic Choice Among Products " Journal of Business Vol 53 (no 3).

[18] Maddalla, G.S. (2001). Limited Dependent and Quantitative Variables in Econometrics. Cambridge: Cambridge University Press; 2001

[19] Mahgoub, S. E., Lesoli, P. P. and Gobotswang, K. (2007) "Awareness and Use of Nutrition Information on Food Packages among Consumers in Maseru" (Lesotho) African Journal, of Food, Agriculture, Nutrition and Development, Vol. 7(6), pp. 1-16.

[20] Manski, C. F. (1997). "Nonparametric Analysis of Randomized Experiments with Missing Covariate and Outcome Data." Working Paper.

[21] Nayga, R. M. (1997) "Impact of Socio-Demographic Factors on Perceived Importance of Nutrition in Food Shopping", Journal of Consumer Affairs, Vol. 31(1), pp. 1-9.

[22] Padel, S. and Foster, C. (2005): Exploring the Gap Between Attitudes and Behaviour: Understanding Why Consumers Buy or Do Not Buy Organic Food. British Food Journal, 107 (8), 606-626.

[23] Philip, D., Kristen, M. and Emma, F. (2010) "Public Attitudes Towards, And Use of, General Food Labelling", Social Science Research Unit Food Standards Agency Unit Report 4

[24] Prestat, C.J. (2001). Market-Orientation: A Possibility to Improve Consumer Acceptability of Pork Products. Masteres Thesis. University of Illinois, Urbana, IL.

[25]Randon, M. and Ashitey, E. (2012). Poultry and Products Brief Annual: Ghana Poultry Annual Report No. 1303. USDA Foreign Agricultural Service Report, Ghana. Global Agricultural Information Network (GAIN) Report.

[26] Sow, T.M, and Grongnet. (2010). Sensory Characteristics for Chicken Meat in Guinea. Poultry Science, 2010, 89 (10), pp.2281-2292

[27] SRID-MoFA (2012). Statistics, Research and Information Directorate of the Ministry of Food and Agriculture ."Agriculture in Ghana: Facts and Figures $2010 "$

[28] Umberger, W.J., Feuz, D.M., Calkins, C.R. and Sitz, B.M. (2003). Country-of-origin Labeling of Beef Products: Us Consumers ${ }^{\text {ee }}$ Perceptions. Journal of Food Distribution Research 34 (3): 103-116

[29] Wiggins, S. and Leturque, H. (2011): Ghana 's Sustained Agricultural Growth: Putting Underused Resources to Work. 